\title{
Preparation of Oligosaccharides by Degradation of Polysaccharides from Chinese Jujube and Its Biological Activity
}

\author{
Xu Yan, ${ }^{1,2}$ Weiwei Wang, ${ }^{2}$ Mengjun Liu $\left(\mathbb{D},{ }^{2}\right.$ and Zhihui Zhao $\mathbb{D}^{1,2}$ \\ ${ }^{1}$ Xinjiang Production \& Construction Corps Key Laboratory of Protection and Utilization of Biological Resources in Tarim Basin, \\ Alar, China \\ ${ }^{2}$ Chinese Jujube Research Center, Hebei Agricultural University, Baoding, China
}

Correspondence should be addressed to Mengjun Liu; 1mj1234567@aliyun.com and Zhihui Zhao; lyzhihuizhao@126.com

Received 8 December 2017; Accepted 13 February 2018; Published 19 April 2018

Academic Editor: Ramar Thangam

Copyright (C) 2018 Xu Yan et al. This is an open access article distributed under the Creative Commons Attribution License, which permits unrestricted use, distribution, and reproduction in any medium, provided the original work is properly cited.

\begin{abstract}
This study examined the degradation of polysaccharides to oligosaccharides in Chinese jujube fruits. Using a response surface model, the degradation conditions of polysaccharides under acid hydrolysis and enzymatic hydrolysis were optimized in laboratory conditions. A degradation rate of $66.9 \%$ was obtained under optimum acid hydrolysis conditions: $0.6 \mathrm{~mol} / \mathrm{L}$ hydrochloric acid, $3 \%$ substrate concentration, and $1 \mathrm{~h}$ reaction time. A degradation rate of $41.4 \%$ was obtained under optimum enzyme hydrolysis conditions: $4.0 \mathrm{~mL}$ cellulose solution $(10 \mathrm{mg} / \mathrm{mL}), 0.3 \mathrm{~mL}$ substrate solution $(20 \mathrm{mg} / \mathrm{mL}), 0.7 \mathrm{~mL}$ citric acid buffer solution (pH 5 ), and $7.3 \mathrm{~h}$ reaction time. Using the stimulation effect for strain J-4 intestinal probiotic proliferation, the biological activity of oligosaccharides was determined. The results showed that the oligosaccharides from enzyme hydrolysis encouraged intestinal probiotic proliferation.
\end{abstract}

\section{Introduction}

Chinese jujube (Ziziphus jujuba Mill.) is a native plant of China that belongs to the genus Ziziphus in the Rhamnaceae family. It is a medicinal plant with a long history ( $>7000$ years) in China, where it is widely distributed (total growing area $>2,000,000 \mathrm{ha}$ ). The fruits and seeds are used in traditional Chinese medicine where they are believed to have blood nourishing, sedation, antitumor, and immunemodulability properties, among others. The fruits are considered a "natural, healthy food" [1].

Response surface methodology (RSM), first introduced by Box [2], is an effective statistical method which can optimize complex processes. There are several recent studies that have used RSM to identify optimized conditions for the extraction of bioactive compounds from different sources [36]. The main advantage of RSM is the reduced number of experimental trials needed to evaluate multiple parameters and their interactions, which makes it less labor-intensive and time-consuming than other approaches [7].

Chinese jujube fruit is well-known for its high sugar content (60-80\% dried; $25-30 \%$ fresh). Our previous studies revealed that jujube fruit is rich in not only glucose, fructose, and sucrose, but polysaccharides [8-10].

As a nondigestible carbohydrate, oligosaccharides are a component of dietary fiber and are of particular interest for their metabolic properties [11]. Particularly, oligosaccharides are considered to have prebiotic properties including the ability to stimulate probiotic bacteria $[12,13]$.

Apart from soybean oligosaccharides and raffinose (produced by direct extraction) and lactulose (produced by an isomerization reaction), the commercial production of oligosaccharides uses enzymatic processes [14]. Plant polysaccharides have been identified as potential sources for oligosaccharide production [15-18].

There is a lack of knowledge on the preparation of oligosaccharides from the degradation of water-soluble polysaccharides in jujube fruits. The objectives of this study were to (1) optimize the degradation conditions of polysaccharides to oligosaccharides using acid hydrolysis and enzymatic hydrolysis and (2) study the biological activity of oligosaccharides.

We believe that the knowledge gained from this study will help to further exploit and improve the utilization value of 
jujube and provide a theoretical support for the development of health food.

\section{Materials and Methods}

2.1. Chemicals. Deionized water was purified by an EPED superpurification system (Eped, Nanjing, China). All other reagent solutions were of analytical grade (Sinopharm Chemical Reagent Co., Ltd., Shanghai, China). Dialysis tubes were from Spectrum Laboratories, Inc. (USA).

2.2. Fruit Material and Treatment. Samples of Chinese jujube "Jinsixiaozao" fruits were collected from Cang County, Cangzhou, China. The trees were managed according to integrated cultivation protocols, with all the fruits transported to the laboratory in isothermal boxes containing ice. The fruits were divided into pulp and shells with a knife. The pulp was cut into thin strips with a knife and dried at $55^{\circ} \mathrm{C}$ in a DGG-9203A constant temperature drying oven (Senxin Experiment Corporation, Shanghai, China). The dried jujube pulp was crushed using a universal highspeed smashing machine (Hongtaiyang Electromechanical Corporation, Yongkang, China), and the smashed dried pulp passed through a 70-mesh sieve. The powder was collected and stored in a desiccator at room temperature $\left(15-20^{\circ} \mathrm{C}\right)$ until needed.

\subsection{Preparation of Oligosaccharides by \\ Polysaccharide Degradation}

2.3.1. Preparation of Polysaccharides. In order to remove lipids in jujube, the jujube powder was refluxed with $80 \%$ ethanol three times for $1.5 \mathrm{~h}$ each time at $100^{\circ} \mathrm{C}$. After filtration, the residue was dried at room temperature and then extracted with boiling water twice for $2 \mathrm{~h}$ each time. The water extract was combined, concentrated, and precipitated with three volumes of $95 \%$ ethanol at $4^{\circ} \mathrm{C}$ overnight. The precipitate was washed with ethanol absolute and deproteinized using the Sevage method [19] before being concentrated and freeze-dried to obtain the crude polysaccharide.

\subsubsection{Selection and Optimization of Acid Hydrolysis Condi-} tions of Polysaccharides. At $90^{\circ} \mathrm{C}$, the appropriate range of relevant factors that affect the degradation rate of polysaccharides (concentration of hydrochloric acid, amount of different substrates, and time of acid hydrolysis) was determined from single factor experiments. The factor levels for each individual experiment were $0.1,0.2,0.5,1.0,1.5$, and $2 \mathrm{~mol} / \mathrm{L}$ hydrochloric acid; $0.2 \%, 0.5 \%, 1.0 \%, 2.0 \%, 3.0 \%$, and $4.0 \%$ of different substrates; and $0.5 \mathrm{~h}, 1.0 \mathrm{~h}, 1.5 \mathrm{~h}, 2.0 \mathrm{~h}, 2.5 \mathrm{~h}$, and $3.0 \mathrm{~h}$ for acid hydrolysis.

RSM was used to optimize the acid hydrolysis conditions of polysaccharides. A Box-Behnken design (BBD) with three independent variables-hydrochloric acid concentration $\left(X_{1}\right)$, substrate $\left(X_{2}\right)$, and acid hydrolysis time $\left(X_{3}\right)$-was used. The input range of the selected variables was determined in preliminary RSM experiments. The three independent variables were coded at three levels $(-1,0,1)$, which resulted in an experimental design with 15 experimental points, including three central points to evaluate the pure error. Design Expert V8.0.6 (Stat-Ease Inc., Minneapolis, USA) was used to design the experiments and analyze the data.

Experimental data were analyzed to fit a second-order polynomial model. The models were predicted through statistical analysis and regression analysis (ANOVA) using Design Expert V8.0.6. This software was also used to obtain the coefficients of the quadratic polynomial model. The quality of the fitted model was expressed by the coefficient of determination $R^{2}$, and its statistical significance was checked with an $F$-test.

2.3.3. Selection and Optimization of Enzymatic Hydrolysis Conditions of Polysaccharides. The reaction system $(5 \mathrm{~mL})$ included the polysaccharide solution $(20 \mathrm{mg} / \mathrm{mL})$, enzyme solution $(10 \mathrm{mg} / \mathrm{mL})$, and citric acid buffer solution ( $\mathrm{pH} 5)$. Different volumes of enzyme solution, substrate, and citric acid buffer solution ( $\mathrm{pH}$ 5) were reacted at $45^{\circ} \mathrm{C}$ in a water bath to degrade the polysaccharides. The single factor test was used to analyze the three factors (amount of enzyme, amount of substrate, and enzymatic hydrolysis time) to identify the appropriate range of each factor. The levels for each factor were $0.5 \mathrm{~mL}, 1 \mathrm{~mL}, 2 \mathrm{~mL}, 3 \mathrm{~mL}$, and $4 \mathrm{~mL}$ of enzyme, $0.5 \mathrm{~mL}$, $1 \mathrm{~mL}, 2 \mathrm{~mL}, 3 \mathrm{~mL}$, and $4 \mathrm{~mL}$ of substrate, and $1 \mathrm{~h}, 2 \mathrm{~h}$, and $3 \mathrm{~h}$ to $8 \mathrm{~h}$ for enzymatic hydrolysis.

Based on the single factor test, a Box-Behnken design (BBD) with three independent variables-amount of different enzymes $\left(X_{1}\right)$, substrate $\left(X_{2}\right)$, and enzymatic hydrolysis time $\left(X_{3}\right)$-was used. The input range of the selected variables was determined in preliminary RSM experiments.

2.3.4. Calculation of Degradation Rate. After polysaccharide degradation, the unhydrolyzed polysaccharides and cellulase were precipitated by adding three volumes of $95 \%$ ethanol and removed by centrifugation. The solution was then dialyzed in a MD10 dialysis tube to remove any small molecules. The inside part was collected and lyophilized to extract the oligosaccharides. The sugar contents in the polysaccharide and oligosaccharide samples were determined using the Calorimetric Dubois Method [20]. The degradation rate (DR) was calculated from the ratio of the sugar content in the oligosaccharide and polysaccharide.

2.4. Activity of Oligosaccharides. Strain J-4 with antagonistic activity against $E$. coli was isolated from the cecum of healthy chickens and provided by the Department of Pharmaceutical Engineering, College of Life Sciences, Hebei Agricultural University.

The basal fermentation medium included $2 \%$ glucose, $2 \%$ peptone, $0.2 \% \mathrm{NaH}_{2} \mathrm{PO}_{4} \cdot 2 \mathrm{H}_{2} \mathrm{O}, 0.4 \% \mathrm{Na}_{2} \mathrm{HPO}_{4} \cdot 2 \mathrm{H}_{2} \mathrm{O}$, $0.05 \% \mathrm{MgSO}_{4} \cdot 5 \mathrm{H}_{2} \mathrm{O}$, and $0.02 \% \mathrm{CaCl}_{2}$ at $\mathrm{pH}$ 7.2-7.4. To determine the effect of the oligosaccharides prepared by polysaccharide degradation on the growth of strain J-4 intestinal probiotics in vitro, oligosaccharides at different concentrations $(0.25 \%, 0.50 \%)$ were added to the basal medium in place of glucose to culture the intestinal probiotics. The growth of bacteria was measured at $600 \mathrm{~nm}$ 
TABLE 1: Box-Behnken design and observed responses.

\begin{tabular}{|c|c|c|c|c|}
\hline Number & Hydrochloric acid concentration $\left(X_{1}\right)$ & Substrate $\left(X_{2}\right)$ & Acid time $\left(X_{3}\right)$ & Hydrolysis degradation rate (\%) \\
\hline (1) & $0(0.5)$ & $-1(2)$ & $1(1.5)$ & 40.01 \\
\hline (2) & $1(0.75)$ & $-1(2)$ & $0(1.0)$ & 40.52 \\
\hline (3) & $0(0.5)$ & $1(4)$ & $-1(0.5)$ & 17.42 \\
\hline (4) & $0(0.5)$ & $1(4)$ & $1(1.5)$ & 55.95 \\
\hline (5) & $1(0.75)$ & $1(4)$ & $0(1.0)$ & 39.48 \\
\hline (6) & $0(0.5)$ & $0(3)$ & $0(1.0)$ & 63.03 \\
\hline (7) & $1(0.75)$ & $0(3)$ & $-1(0.5)$ & 40.52 \\
\hline (8) & $0(0.5)$ & $0(3)$ & $0(1.0)$ & 65.89 \\
\hline (9) & $1(0.75)$ & $0(3)$ & $1(1.5)$ & 39.06 \\
\hline$(10)$ & $0(0.5)$ & $-1(2)$ & $-1(0.5)$ & 39.91 \\
\hline (11) & $-1(0.25)$ & $0(3)$ & $-1(0.5)$ & 13.27 \\
\hline (12) & $0(0.5)$ & $0(3)$ & $0(1.0)$ & 66.69 \\
\hline (13) & $-1(0.25)$ & $1(4)$ & $0(1.0)$ & 23.13 \\
\hline (14) & $-1(0.25)$ & $-1(2)$ & $0(1.0)$ & 9.90 \\
\hline (15) & $-1(0.25)$ & $0(3)$ & $1(1.5)$ & 23.49 \\
\hline
\end{tabular}

wavelength $\left(\mathrm{OD}_{600}\right)$ at $12 \mathrm{~h}, 14 \mathrm{~h}$, and $16 \mathrm{~h}$ into the culture period [21].

2.5. Statistical Analysis. All of the experiments were conducted in triplicate. $P$ values $<0.05$ and $<0.01$ were regarded as significant and highly significant, respectively. The direction and magnitude of the correlation between the variables were quantified by the square of the correlation coefficient, $R$.

\section{Results}

3.1. Optimization of Acid Hydrolysis from Jujube Polysaccharides. Acid hydrolysis was used to extract polysaccharides from Chinese jujube "Jinsixiaozao." The operational parameters were optimized using the Box-Behnken design based on RSM. All experimental data obtained from the 15-run experiment are shown in Table 1.

Experimental values for the extraction efficiency of the degradation conditions of polysaccharide by acid hydrolysis (Table 1) were analyzed using multiple regressions to fit the second-order regression equation, and the regression model in terms of coded factors was predicted as follows:

$$
\begin{aligned}
Y= & 65.203+11.224 X_{1}+0.709 X_{2}+5.92 X_{3} \\
& -3.568 X_{1} X_{2}-2.92 X_{1} X_{3}+9.60 X_{2} X_{3} \\
& -23.095 X_{1}{ }^{2}-13.85 X_{2}{ }^{2}-13.023 X_{3}{ }^{2} .
\end{aligned}
$$

$Y$ denotes the response function (DR) and $X_{1}, X_{2}$, and $X_{3}$ are the encoded values of the three independent variables.

The coefficients in (1) were calculated using RSM, and statistical analysis of the experimental data was used to establish the best-fit model for the independent variables. The model had a satisfactory level of adequacy $\left(R^{2}\right)$ (Table 2). The response values were significantly affected by all three parameters, suggesting that they were directly related to the degradation rate.

The analysis of variance (ANOVA) of the model is shown in Table 2 . The calculated model explained $96.59 \%$ of the polysaccharide degradation rate. Moreover, the adjusted correlation coefficient of determination $\left(\right.$ RAdj $\left.^{2}\right)$ of the equation was 0.9044 , which suggests an excellent correlation between any two independent variables. The corresponding variables would be more significant if the absolute $F$-value increased and the $P$ value decreased. The statistical analysis produced a high $F$-value (15.7242) and a very low $P$ value $(P<0.01)$, which implies that the model is significant. Lack of fit ( $P=0.0667$, not significant) confirmed the validity of the model. The results indicate that the model worked well for the analysis and prediction of degradation conditions of polysaccharide using acid hydrolysis. Table 2 shows that $X_{2}, X_{1} X_{2}$, and $X_{1} X_{3}$ had no significant effect on the oligosaccharide conversion.

According to the regression equation of the model, fixing a factor in the encoding value " 0 " level, the effect of two factors was analyzed on the conversion rate of oligosaccharides in the process of acid degradation by Expert Design software (Figure 1). The 3D response surface plots showed that when the acid concentration was at $0.5 \mathrm{~mol} / \mathrm{L}$, substrate concentration and time affected the conversion rate (Figure 1); the substrate and acid concentration affected the degradation rate when the time was at $1.0 \mathrm{~h}$; and when the substrate concentration was 3.0\%, the other two factors affected the degradation rate. There was an extreme value in the selected range which was the highest point of response surface.

According to the results of 15 experiments, the predicted optimized conditions- $0.6 \mathrm{~mol} / \mathrm{L}$ hydrochloric acid, $3.1 \%$ substrate concentration, and $1.1 \mathrm{~h}$ of acid hydrolysisproduced a conversion rate of $67.2 \%$. To confirm the accuracy of the model, three verification tests were carried out, and the conditions were slightly modified to make them more feasible $-0.6 \mathrm{~mol} / \mathrm{L}$ hydrochloric acid, $3 \%$ substrate concentration, and $1 \mathrm{~h}$ of acid hydrolysis - and produced a degradation rate of $66.9 \%$, which was close to the predicted value. Therefore, we believe that this model is credible. 
TABLE 2: Estimated regression coefficients for quadratic polynomial model and ANOVA for the experimental results.

\begin{tabular}{|c|c|c|c|c|c|c|}
\hline Source $^{\mathrm{a}}$ & Sum of squares & $\mathrm{df}^{\mathrm{b}}$ & Mean square & $F$-value & $P$ value & Significance \\
\hline Model & 4659.3052 & 9 & 517.7006 & 15.7242 & 0.0037 & $* *$ \\
\hline$X_{1}$ & 1007.7805 & 1 & 1007.7805 & 30.6095 & 0.0026 & $* *$ \\
\hline$X_{2}$ & 4.0186 & 1 & 4.0186 & 0.1221 & 0.7410 & \\
\hline$X_{3}$ & 280.3712 & 1 & 280.3712 & 8.5158 & 0.0331 & * \\
\hline$X_{1} X_{2}$ & 50.9082 & 1 & 50.9082 & 1.5462 & 0.2688 & \\
\hline$X_{1} X_{3}$ & 34.1056 & 1 & 34.1056 & 1.0359 & 0.3555 & \\
\hline$X_{2} X_{3}$ & 368.6400 & 1 & 368.6400 & 11.1968 & 0.0204 & * \\
\hline$X_{1}^{2}$ & 1969.4705 & 1 & 1969.4705 & 59.8190 & 0.0006 & $* *$ \\
\hline$X_{2}^{2}$ & 708.3103 & 1 & 708.3103 & 21.5136 & 0.0056 & $* *$ \\
\hline$X_{3}^{2}$ & 626.2019 & 1 & 626.2019 & 19.0197 & 0.0073 & $* *$ \\
\hline Residual & 164.6191 & 5 & 32.9238 & & & \\
\hline Lack of fit & 157.2140 & 3 & 52.4047 & 14.1537 & 0.0667 & Not significant \\
\hline Pure error & 7.4051 & 2 & 3.7025 & & & \\
\hline Cor total & 4823.9243 & 14 & & & & \\
\hline RAdj $^{2}=0.9044$ & $R^{2}=0.9659$ & & & & & \\
\hline
\end{tabular}

${ }^{\mathrm{a}}$ Coefficient refers to the general model. ${ }^{\mathrm{b}}$ Degrees of freedom. ${ }^{*}$ Significant $(P<0.05) .{ }^{* *}$ Highly significant $(P<0.01)$.

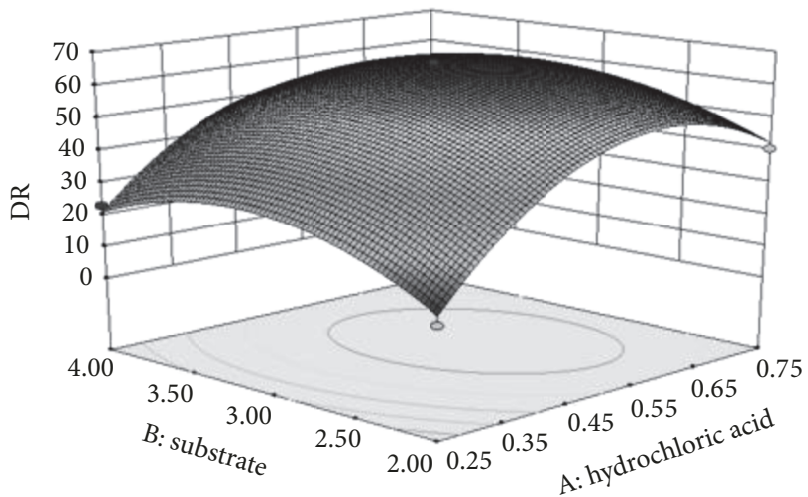

(a)

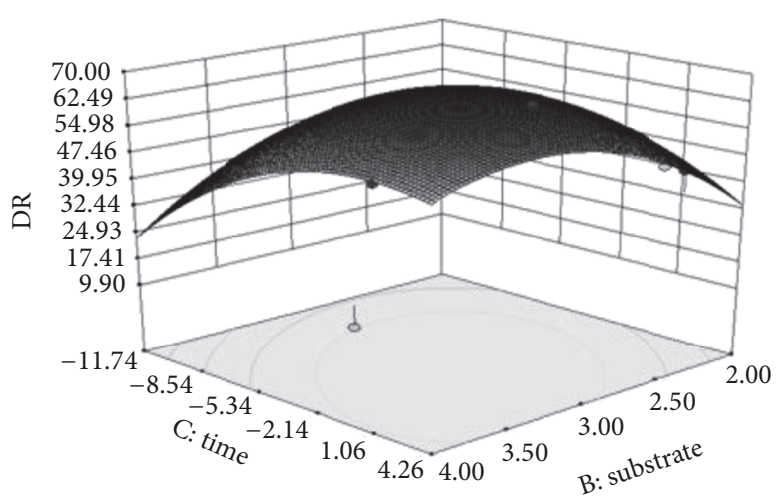

(b)

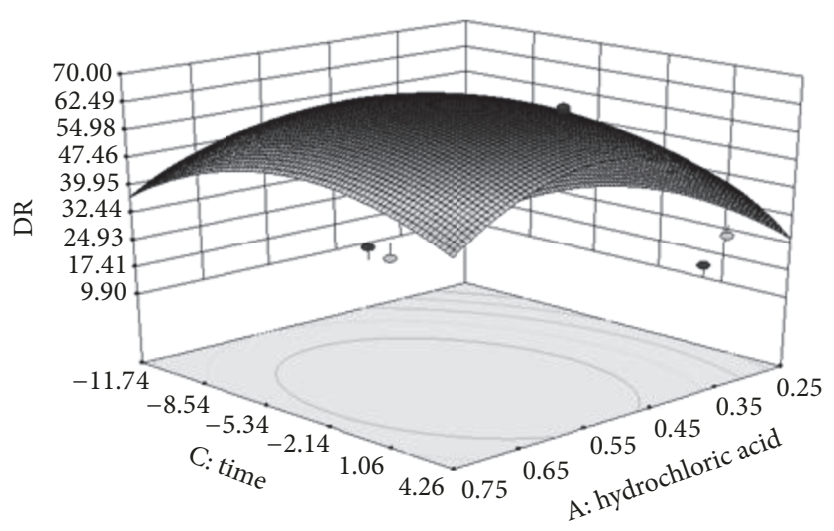

(c)

FIGURE 1: Response surface plot for acid degradation of polysaccharides on the effect of (a) varying hydrochloric acid concentration (mol/L) and substrate percentage (\%), (b) varying time (h) and substrate percentage (\%), and (c) varying time (h) and hydrochloric acid concentration $(\mathrm{mol} / \mathrm{L})$. 
TABLE 3: Box-Behnken design and observed responses.

\begin{tabular}{lcccc}
\hline Number & Amount of different enzymes $\left(X_{1}\right)$ & Substrate $\left(X_{2}\right)$ & Enzymatic hydrolysis time $\left(X_{3}\right)$ & Degradation rate $(\%)$ \\
\hline$(1)$ & $0(4)$ & $0(0.5)$ & $0(7)$ & 39.0 \\
$(2)$ & $1(4.5)$ & $1(0.75)$ & $0(7)$ & 23.4 \\
$(3)$ & $1(4.5)$ & $0(0.5)$ & $-1(6)$ & $0(7)$ \\
$(4)$ & $0(4)$ & $0(0.5)$ & $1(8)$ & 40.5 \\
$(5)$ & $-1(3.5)$ & $0(0.5)$ & $1(8)$ & 28.2 \\
$(6)$ & $1(4.5)$ & $0(0.5)$ & $0(7)$ & 30.1 \\
$(7)$ & $0(4)$ & $0(0.5)$ & $-1(6)$ & 10.7 \\
$(8)$ & $-1(3.5)$ & $0(0.5)$ & $-1(6)$ & 12.5 \\
$(9)$ & $0(4)$ & $1(0.75)$ & $0(7)$ & 35.1 \\
$(10)$ & $1(4.5)$ & $-1(0.25)$ & $1(8)$ & 30.1 \\
$(11)$ & $0(4)$ & $-1(0.25)$ & $0(7)$ & 25.1 \\
$(12)$ & $-1(3.5)$ & $-1(0.25)$ & $1(8)$ & 25.5 \\
$(13)$ & $0(4)$ & $1(0.75)$ & $0(7)$ & 10.7 \\
$(14)$ & $-1(3.5)$ & $1(0.75)$ & $-1(6)$ & 28.5 \\
\hline$(15)$ & $0(4)$ & $-1(0.25)$ & \\
\hline
\end{tabular}

TABLE 4: Estimated regression coefficients for quadratic polynomial model and ANOVA for the experimental results.

\begin{tabular}{|c|c|c|c|c|c|c|}
\hline Source $^{a}$ & Sum of squares & $\mathrm{df}^{\mathrm{b}}$ & Mean square & $F$-value & $P$ value & Significant \\
\hline Model & 1454.6438 & 9 & 161.6271 & 23.4274 & 0.0014 & $* *$ \\
\hline$X_{1}$ & 374.9691 & 1 & 374.9691 & 54.3507 & 0.0007 & $* *$ \\
\hline$X_{2}$ & 273.1953 & 1 & 273.1953 & 39.5989 & 0.0015 & $* *$ \\
\hline$X_{3}$ & 214.0381 & 1 & 214.0381 & 31.0242 & 0.0026 & $* *$ \\
\hline$X_{1} X_{2}$ & 1.8090 & 1 & 1.8090 & 0.2622 & 0.6304 & \\
\hline$X_{1} X_{3}$ & 2.2500 & 1 & 2.2500 & 0.3261 & 0.5927 & \\
\hline$X_{2} X_{3}$ & 32.6041 & 1 & 32.6041 & 4.7259 & 0.0817 & \\
\hline$X_{1}^{2}$ & 181.8072 & 1 & 181.8072 & 26.3524 & 0.0037 & $* *$ \\
\hline$X_{2}{ }^{2}$ & 302.2143 & 1 & 302.2143 & 43.8051 & 0.0012 & $* *$ \\
\hline$X_{3}^{2}$ & 153.8276 & 1 & 153.8276 & 22.2969 & 0.0052 & $* *$ \\
\hline Residual & 34.4953 & 5 & 6.8991 & & & \\
\hline Lack of fit & 33.2545 & 3 & 11.0848 & 17.8663 & 0.0535 & Not significant \\
\hline Pure error & 1.2409 & 2 & 0.6204 & & & \\
\hline Cor total & 1489.1391 & 14 & & & & \\
\hline$R_{\mathrm{Adj}}{ }^{2}=0.9351$ & $R^{2}=0.9768$ & & & & & \\
\hline
\end{tabular}

${ }^{\mathrm{a}}$ Coefficient refers to the general model. ${ }^{\mathrm{b}}$ Degrees of freedom. ${ }^{* *}$ Highly significant $(P<0.01)$.

3.2. Optimization of Enzymatic Hydrolysis from Jujube Polysaccharide. All experimental data obtained from 15-run experiment are shown in Table 3. Experimental values for the extraction efficiency of degradation conditions of polysaccharide using enzymatic hydrolysis (Table 3) were analyzed using multiple regressions to fit the second-order regression equation, and the regression model in terms of coded factors was predicted as follows:

$$
\begin{aligned}
Y= & 39.6+6.8 X_{1}-5.8 X_{2}+5.2 X_{3}+0.7 X_{1} X_{2} \\
& -0.8 X_{1} X_{3}+2.9 X_{2} X_{3}-7.0 X_{1}^{2}-9.0 X_{2}^{2} \\
& -6.5 X_{3}^{2} .
\end{aligned}
$$

$Y$ denotes the response function (DR) and $X_{1}, X_{2}$, and $X_{3}$ are the encoded values of the three independent variables.
The coefficients of (2) were calculated using RSM, and statistical analysis of the experimental data was used to establish the best-fit model for the independent variables. The model had satisfactory levels of adequacy $\left(R^{2}\right)$ (Table 4$)$. The response values were significantly affected by all three parameters, suggesting that they were directly related to the degradation rate.

The ANOVA result of the model is shown in Table 4. The calculated model explained $97.7 \%$ of the degradation rate. Moreover, the adjusted correlation coefficient of determination $\left(\mathrm{RAdj}^{2}\right)$ was 0.9351 , which suggests an excellent correlation between any two independent variables. The statistical analysis produced a high $F$-value (23.4) and a very low $P$ value $(P<0.01)$, implying that the model was significant. Lack of fit $(P=0.0535$, not significant) confirmed the validity of the model. The results indicate that the model 


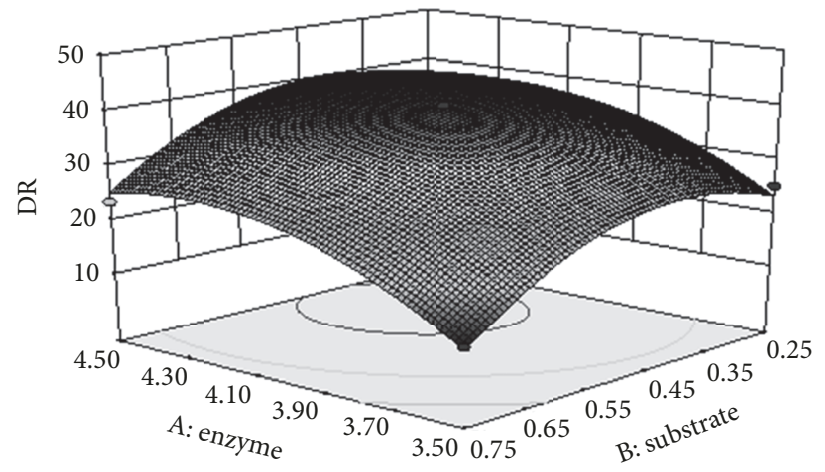

(a)

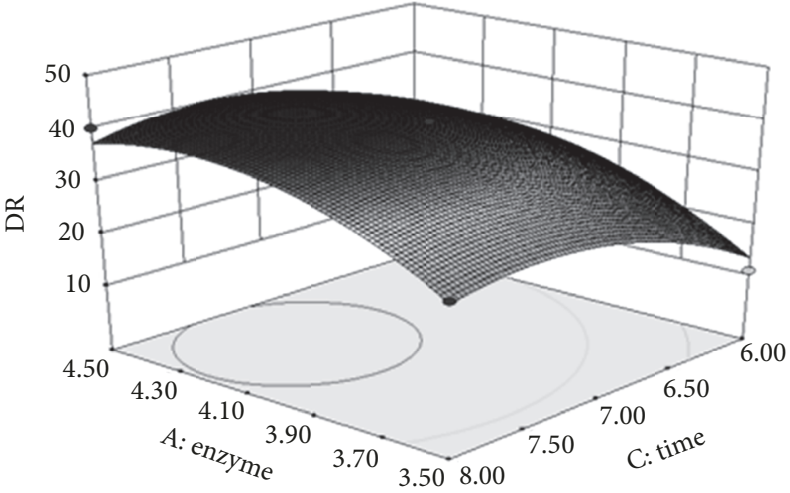

(b)

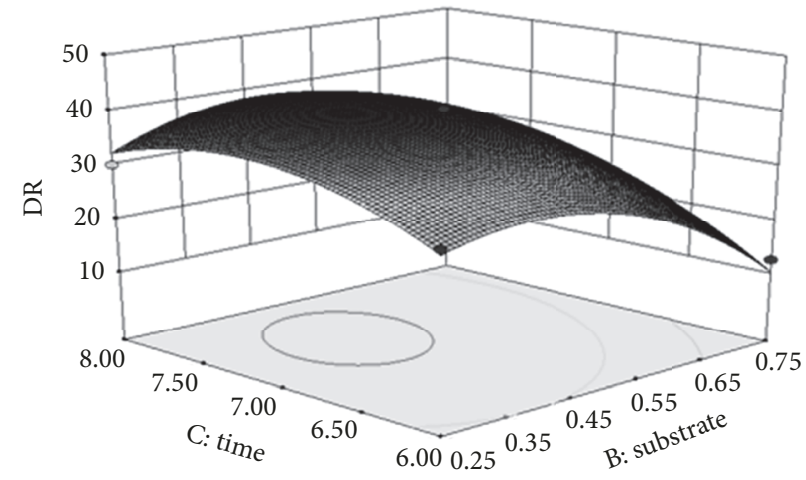

(c)

FIGURE 2: Response surface plot for acid degradation of polysaccharides on the effect of (a) varying enzyme concentration (mL) and substrate concentration $(\mathrm{mL}),(\mathrm{b})$ varying time (hour) and enzyme concentration $(\mathrm{mL})$, and $(\mathrm{c})$ varying time (hour) and substrate concentration $(\mathrm{mL})$.

could work well for the analysis and prediction of degradation conditions of polysaccharide by enzymatic hydrolysis. Table 4 shows that $X_{1} X_{2}, X_{1} X_{3}$, and $X_{2}$ do not have a significant effect on the oligosaccharide conversion rate, while the others were significant.

The 3D response surface plots show that, with $4 \mathrm{~mL}$ of enzyme, the substrate concentration and enzyme time affected the conversion rate (Figure 2); at $7.0 \mathrm{~h}$, the substrate and enzyme amount affected the rate; and at $0.5 \mathrm{~mL}$ of substrate, the enzyme amount and time affected the rate. There was an extreme value in the selected range which was the highest point of the response surface.

To confirm the accuracy of the model, three verification tests were carried out, and the conditions were slightly modified to make them more feasible $-4.0 \mathrm{~mL}$ of enzyme $(10 \mathrm{mg} / \mathrm{mL}), 0.3 \mathrm{~mL}$ of substrate $(20 \mathrm{mg} / \mathrm{mL}), 0.7 \mathrm{~mL}$ of citric acid buffer solution ( $\mathrm{pH} 5)$, and $7.3 \mathrm{~h}$ of enzymatic hydrolysis - and produced a conversion rate of $41.4 \%$, which was close to the predicted value. Therefore, we believe that this model is credible.

3.3. Biological Activity of Oligosaccharides. The effect of different concentrations and different sources of Chinese jujube oligosaccharides on the promotion of intestinal probiotics was determined in vitro. Glucose in basal culture medium was replaced by different concentrations of oligosaccharides that had been prepared by polysaccharide hydrolysis as a carbon source. Since the concentration of bacterial suspension was proportional to the turbidity, the $\mathrm{OD}_{600}$ value of fermentation liquor was monitored every two hours after inoculation for bacterial growth.

The activities of two types of oligosaccharides, prepared using different methods, were determined with strain J-4 intestinal probiotics.

With the oligosaccharide from acid hydrolysis, strain J-4 intestinal probiotics had a significantly lower growth rate than that of the basal culture medium (Figure 3). It is suggested that oligosaccharide obtained by acid hydrolysis has low activity. The oligosaccharide obtained by enzyme hydrolysis had a significantly higher growth rate of J-4 intestinal probiotics than the basal medium $(P<0.05$; Figure 4).

\section{Discussion}

According to our research (data not shown), Chinese jujube fruits have low levels of natural oligosaccharides. It is difficult to extract oligosaccharides from the fruit directly. However, the content of jujube polysaccharides in the fruit is somewhat higher $[22,23]$. It is reported that the high degree of polymerization, large molecular space, and low bioavailability have greatly restricted the application of polysaccharides in the food, pharmaceutical, and chemical industries and other fields [24]. It can, however, be degraded to oligosaccharides. 


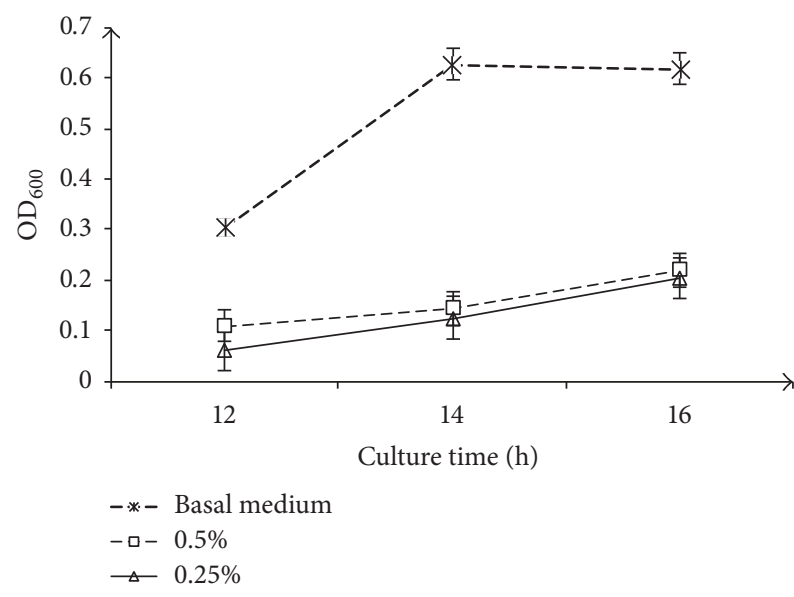

FIgURE 3: The influence of different concentrations of oligosaccharide from acid hydrolysis of jujube polysaccharides on strain J4 intestinal probiotics (bacterial growth determined by measuring OD $600 \mathrm{~nm}$ at $12 \mathrm{~h}, 14 \mathrm{~h}$, and $16 \mathrm{~h}$ into the culturing period). Values represent the mean of at least three biological replicates \pm standard error of the mean.

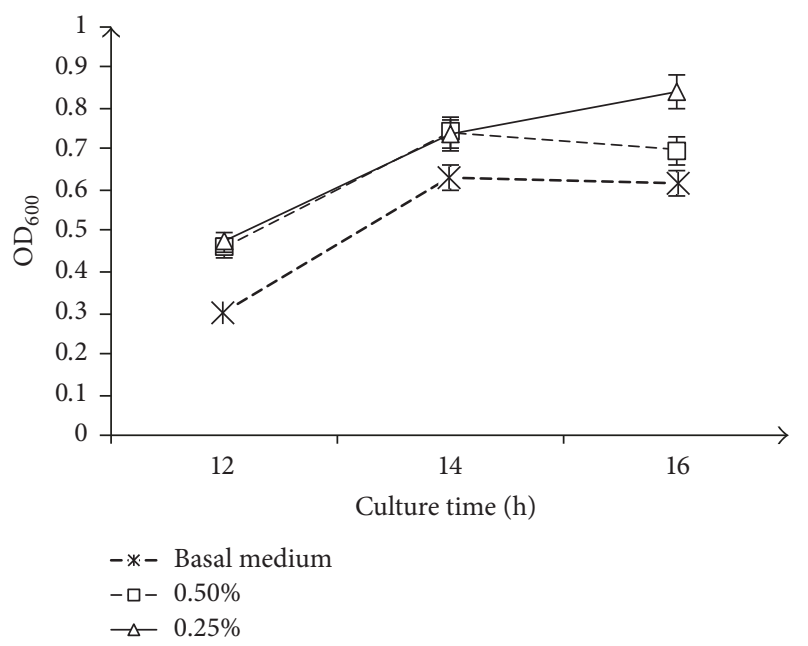

FIGURE 4: The influence of different concentrations of enzyme hydrolysis products of jujube polysaccharide on strain J-4 intestinal probiotics (bacterial growth determined by measuring $\mathrm{OD}_{600 \mathrm{~nm}}$ at $12 \mathrm{~h}, 14 \mathrm{~h}$, and $16 \mathrm{~h}$ into the culturing period). Values represent the mean of at least three biological replicates \pm standard error of the mean.

Oligosaccharides formed by hydrolysis have a variety of biological activities [25]. In this study, two methods were used to prepare the oligosaccharides-acid hydrolysis and enzyme hydrolysis - which produced degradation rates of $66.9 \%$ and $41.4 \%$, respectively. Moreover, the degradation rates were higher than that of other plants [24, 26, 27].

The yield of oligosaccharides prepared by enzyme hydrolysis was lower than those prepared by acid hydrolysis. However the activity of enzyme hydrolysis oligosaccharides was higher than that from acid hydrolysis. Wang believes that the reaction conditions of acid hydrolysis are more severe-destroying the structure of sugar-than the milder enzyme hydrolysis [28]. This may explain why the enzyme hydrolysis oligosaccharides had better activity on strain J-4 intestinal probiotics.

In this study, we extracted oligosaccharides through polysaccharide degradation of Chinese jujube. The exact structural information and bioactivities of these oligosaccharides need further study.

This experiment has laid a foundation for further studies on the degradation of jujube polysaccharides and provided a reference for the development of new functional oligosaccharides and a new direction for the development and utilization of Chinese jujube.

\section{Conclusions}

By incorporating a response surface model, the degradation conditions of jujube polysaccharides using acid hydrolysis and enzyme hydrolysis were studied. The optimum acid hydrolysis conditions were $0.6 \mathrm{~mol} / \mathrm{L}$ hydrochloric acid, $3 \%$ substrate concentration, and a $1 \mathrm{~h}$ reaction time. The optimum enzyme hydrolysis conditions were $4.0 \mathrm{~mL}$ of enzyme $(10 \mathrm{mg} / \mathrm{mL}), 0.3 \mathrm{~mL}$ of substrate $(20 \mathrm{mg} / \mathrm{mL}), 0.7 \mathrm{~mL}$ of citric acid buffer solution ( $\mathrm{pH}$ 5), and $7.3 \mathrm{~h}$ of enzymatic hydrolysis. Under these conditions, the degradation rate of acid hydrolysis and enzyme hydrolysis was $66.9 \%$ and $41.4 \%$, respectively. The oligosaccharides from enzyme hydrolysis encouraged intestinal probiotic proliferation.

\section{Conflicts of Interest}

The authors declare that they have no conflicts of interest.

\section{Acknowledgments}

This work was funded by Xinjiang Production \& Construction Corps Key Laboratory of Protection and Utilization of Biological Resources in Tarim Basin (BRZD1302), Young Academic Leaders Project of Hebei Agricultural University, and Top-Notch Talent Support Project of Hebei Province.

\section{References}

[1] M. Liu, "Chinese Jujube: Botany and Horticulture," Horticultural Reviews, vol. 32, pp. 229-298, 2006.

[2] G. E. P. Box and N. R. Draper, "Introduction to response surface methodology," Response Surfaces, Mixtures, and Ridge Analyses, pp. 1-16, 2006.

[3] N. Ilaiyaraja, K. R. Likhith, G. R. Sharath Babu, and F. Khanum, "Optimisation of extraction of bioactive compounds from Feronia limonia (wood apple) fruit using response surface methodology (RSM)," Food Chemistry, vol. 173, pp. 348-354, 2015.

[4] B. Guldiken, D. Boyacioglu, and E. Capanoglu, "Optimization of Extraction of Bioactive Compounds from Black Carrot Using Response Surface Methodology (RSM)," Food Analytical Methods, vol. 9, no. 7, pp. 1876-1886, 2016.

[5] V. Kumar and H. K. Sharma, "Process optimization for extraction of bioactive compounds from taro (Colocasia esculenta), using RSM and ANFIS modeling," Journal of Food Measurement and Characterization, vol. 11, no. 2, pp. 704-718, 2017. 
[6] V. Ganesan, V. Gurumani, S. Kunjiappan, T. Panneerselvam, and B. Somasundaram, "Optimization and analysis of microwaveassisted extraction of bioactive compounds from Mimosa pudica L. using RSM ANFIS modeling," Journal of Food Measurement and Characterization, 2017.

[7] K. Zhong and Q. Wang, "Optimization of ultrasonic extraction of polysaccharides from dried longan pulp using response surface methodology," Carbohydrate Polymers, vol. 80, no. 1, pp. 19-25, 2010.

[8] Z. Zhao, J. Li, X. Wu et al., "Structure and immunological activity of a pectic polysaccharide from the fruits of Ziziphus jujuba Mill. cv. jinsixiaozao Hort," Chemistry of Natural Compounds, vol. 43, pp. 374-376, 2007.

[9] Z. Zhao, M. Liu, and P. Tu, "Characterization of water soluble polysaccharides from organs of Chinese Jujube (Ziziphus jujuba Mill. cv. dongzao)," European Food Research and Technology, vol. 226, no. 5, pp. 985-989, 2008.

[10] Z. Zhao, J. Li, X. Wu et al., "Structures and immunological activities of two pectic polysaccharides from fruits of Ziziphus jujuba Mill. cv. Jinsixiaozao Hort," Food Research International, vol. 39, no. 8, pp. 917-923, 2006.

[11] J. M. Laparra, E. Tako, R. P. Glahn, and D. D. Miller, "Supplemental inulin does not enhance iron bioavailability to Caco-2 cells from milk- or soy-based, probiotic-containing, yogurts but incubation at $37 \circ \mathrm{C}$ does," Food Chemistry, vol. 109, no. 1, pp. 122-128, 2008.

[12] M. B. Akin, M. S. Akin, and Z. Kirmaci, "Effects of inulin and sugar levels on the viability of yogurt and probiotic bacteria and the physical and sensory characteristics in probiotic ice-cream," Food Chemistry, vol. 104, no. 1, pp. 93-99, 2007.

[13] F. C. A. Buriti, H. R. Cardarelli, T. M. C. C. Filisetti, and S. M. I. Saad, "Synbiotic potential of fresh cream cheese supplemented with inulin and Lactobacillus paracasei in co-culture with Streptococcus thermophilus," Food Chemistry, vol. 104, no. 4, pp. 1605-1610, 2007.

[14] S. I. Mussatto and I. M. Mancilha, "Non-digestible oligosaccharides: A review," Carbohydrate Polymers, vol. 68, no. 3, pp. 587597, 2007.

[15] G. G. Dutton, K. L. Mackie, A. V. Savage, D. Rierger-Hug, and S. Stirm, "Preparation of oligosaccharides by bacteriophage degradation of polysaccharides from Klebsiella serotypes K21 and K32," Carbohydrate Research, vol. 84, no. 1, pp. 161-170, 1980.

[16] M. Lahaye, M. Brunel, and E. Bonnin, "Fine chemical structure analysis of oligosaccharides produced by an ulvan-lyase degradation of the water-soluble cell-wall polysaccharides from Ulua sp. (Ulvales, Chlorophyta)," Carbohydrate Research, vol. 304, no. 3-4, pp. 325-333, 1997.

[17] Z.-Y. Zhu, J.-Y. Zhang, F. Liu, L. Chen, L.-J. Chen, and Y. Tang, "Characterization and lymphocyte proliferation activity of an oligosaccharide degraded from Astragalus polysaccharide," MedChem Comm, vol. 8, no. 7, pp. 1521-1530, 2017.

[18] N. Khodaei and S. Karboune, "Enzymatic generation of galactose-rich oligosaccharides/oligomers from potato rhamnogalacturonan i pectic polysaccharides," Food Chemistry, vol. 197, pp. 406-414, 2016.

[19] L. Navarini, R. Gilli, V. Gombac, A. Abatangelo, M. Bosco, and R. Toffanin, "Polysaccharides from hot water extracts of roasted Coffea arabica beans: Isolation and characterization," Carbohydrate Polymers, vol. 40, no. 1, pp. 71-81, 1999.

[20] M. Dubois, K. A. Gilles, J. K. Hamilton, P. A. Rebers, and F. Smith, "Colorimetric method for determination of sugars and related substances," Analytical Chemistry, vol. 28, no. 3, pp. 350356, 1956.

[21] V. D. Badwaik, L. M. Vangala, D. S. Pender et al., "Sizedependent antimicrobial properties of sugarencapsulated gold nanoparticles synthesized by a green method," Nanoscale Research Letters, vol. 7, no. 1, p. 623, 2012.

[22] H. Rostami and S. M. T. Gharibzahedi, "Microwave-assisted extraction of jujube polysaccharide: optimization, purification and functional characterization," Carbohydrate Polymers, vol. 143, pp. 100-107, 2016.

[23] B. Wang, "Chemical characterization and Ameliorating effect of polysaccharide from Chinese jujube on intestine oxidative injury by ischemia and reperfusion," International Journal of Biological Macromolecules, vol. 48, no. 3, pp. 386-391, 2011.

[24] K. Hu, Q. Liu, S. Wang, and K. Ding, "New oligosaccharides prepared by acid hydrolysis of the polysaccharides from Nerium indicum Mill and their anti-angiogenesis activities," Carbohydrate Research, vol. 344, no. 2, pp. 198-203, 2009.

[25] F. A. de Moura, F. T. Macagnan, and L. P. da Silva, "Oligosaccharide production by hydrolysis of polysaccharides: A review," International Journal of Food Science \& Technology, vol. 50, no. 2, pp. 275-281, 2015.

[26] S. Liu, X. Wan, and X. Du, "Enzymatic preparation of cellooligosaccharides from Radix puerariae fiber," Food Science, vol. 23, no. 4, pp. 66-70, 2012.

[27] S. Huang, Z. Wang, and X. Liu, "Study on enzymatic degradation of tea polysaccharide," China Feed, vol. no. 16, pp. 39-41, 2012.

[28] F. Wang, G. Hu, J. Xiao, and Y. Liu, "Improvement in the productivity of xylooligosaccharides from rice straw by feed xylanase with ultrafiltration," Archives of Biological Sciences, vol. 63, no. 1, pp. 161-166, 2011. 


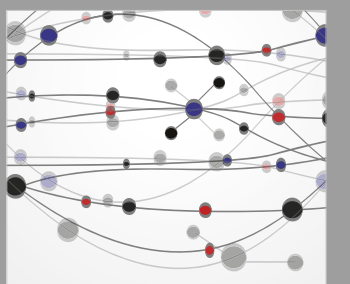

The Scientific World Journal
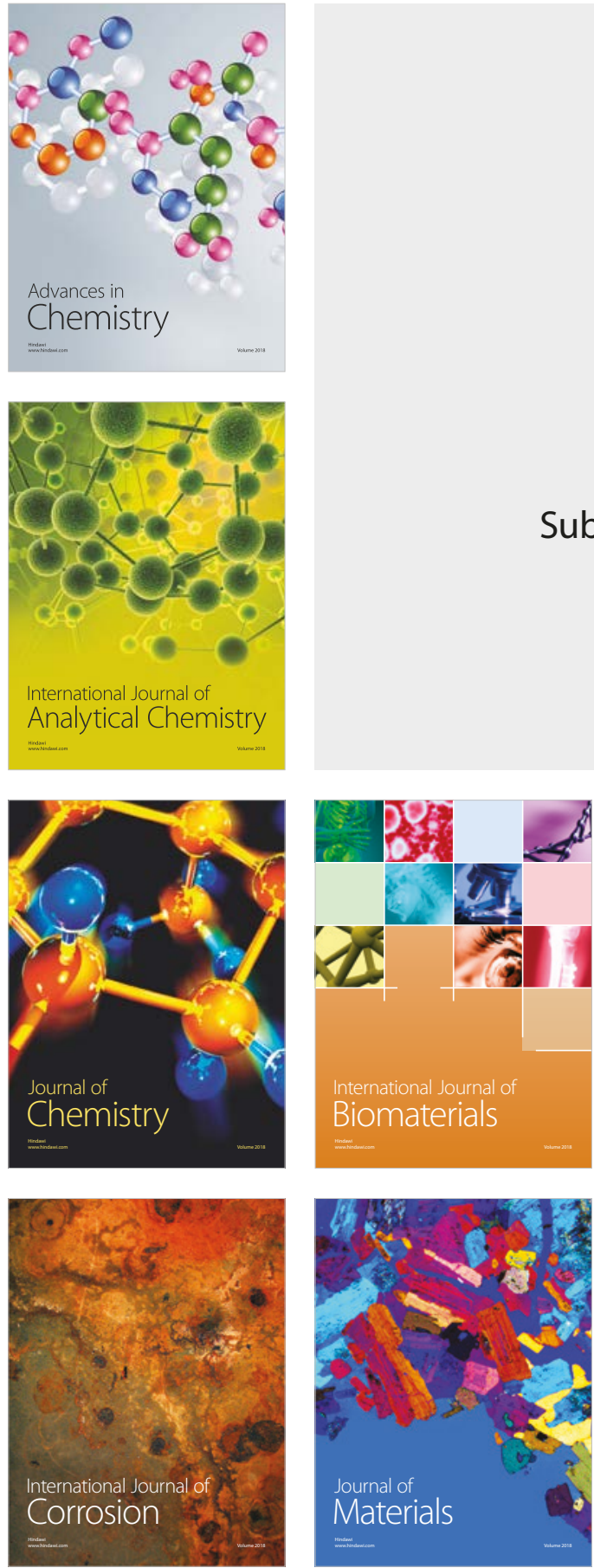

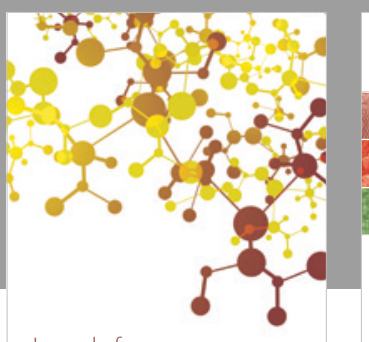

Journal of

Applied Chemistry
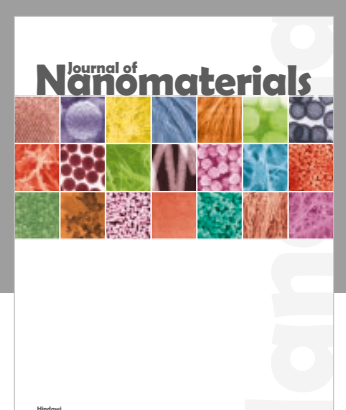

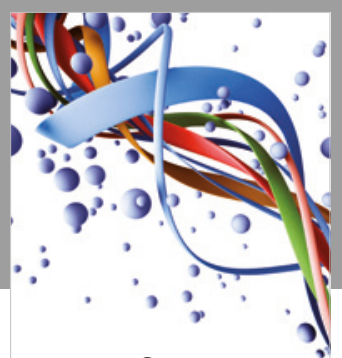

Scientifica

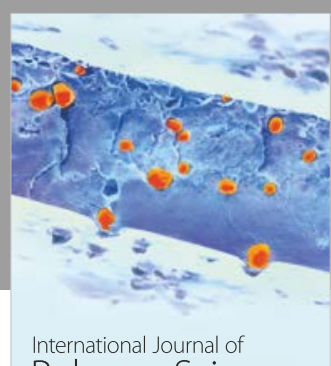

Polymer Science

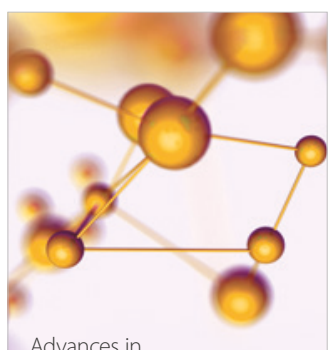

Physical Chemistry
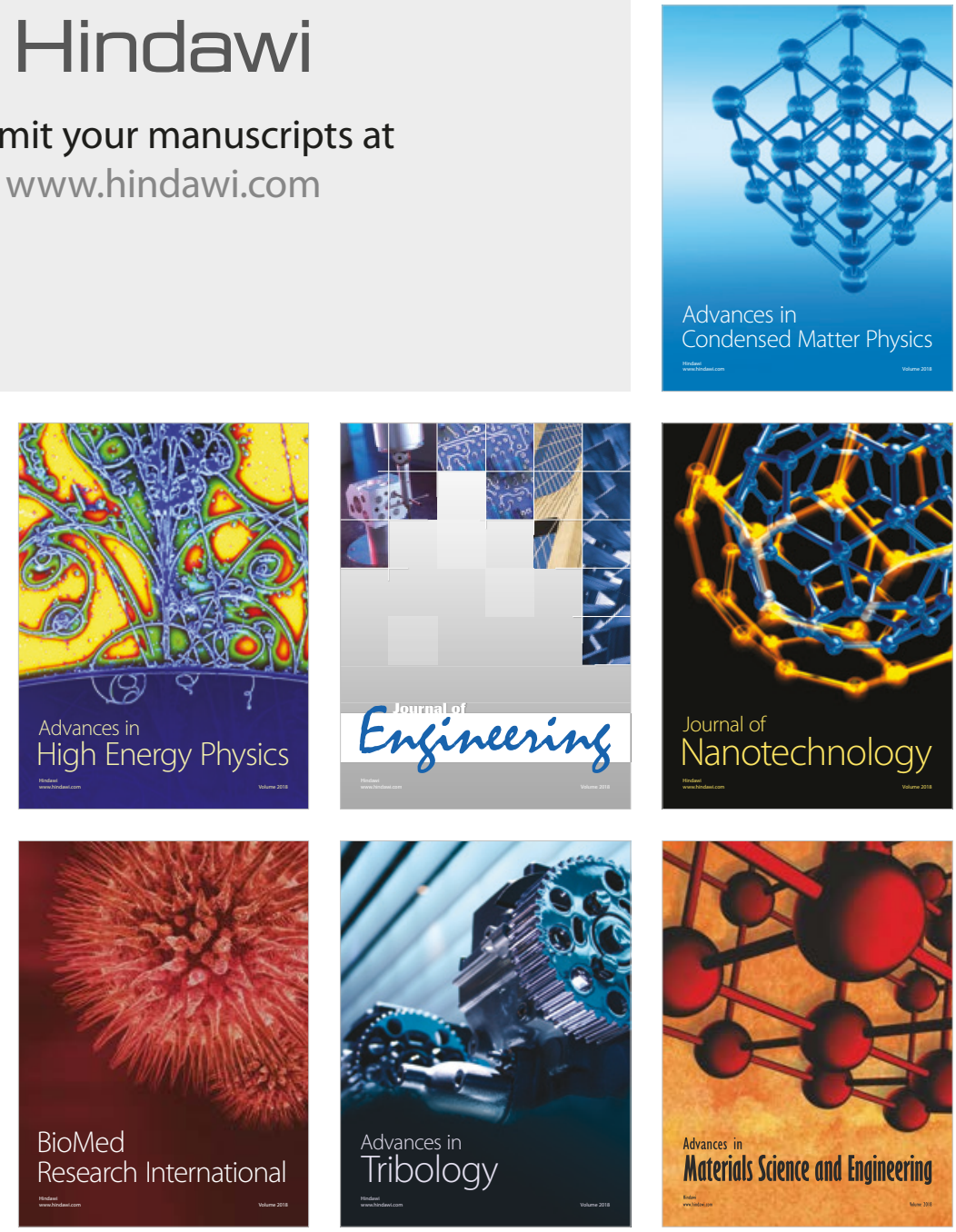